\title{
Implementing a Flipped Classroom Structure in Engineering Education to Improve the Soft Skills
}

\author{
El haini Jamila \\ Laboratory LISA, National School of Applied Sciences, Fez \\ Morocco j.elhaini@gmail.com
}

\begin{abstract}
The fourth industrial revolution or industry 4.0 which is a consequence of the rapid change of information is characterized by ultra-connected and flexible processes in order to develop rapidly a personalized product to be utilized in a limited time. This revolution requires new competencies named the soft skills. So, the challenge for educators is to train students with the soft skills needed in the industry 4.0.

This is why; the flipped classroom method with a new structure based on PowerPoint presentation was implemented for the maintenance and operating reliability's course during the first semester of the 2018-2019 academic year. The flipped course was delivered for the industrial engineering class in their fourth year of engineering studies in the National School of Applied Sciences NSAS, Fez Morocco.
\end{abstract}

The flipped classroom method is being implemented in a growing number of higher education institutions, but a new structure is proposed which aims to improve the engineering students' soft skills especially the lifelong learning, critical thinking, curiosity, autonomy and communication and

\section{El haini Jamila}

Laboratory LISA, National School of Applied Sciences, Fez Morocco

j.elhaini@gmail.com presentation techniques in order to success in this digital age and to meet the industry 4.0 requirements.

The results of an anonymous survey and a t test are very satisfactory and show that this method has a very positive feedback from the students. A t test is a statistic test that permits to compare between the means of two groups.

For me, I can approve that this method is a rewarding teaching experience with minimum technical, technological and logistical resources, but it requires more effort from the teacher who becomes rather a coach and a facilitator and also from the students.

Keywords : Industry 4.0. Soft skills. Flipped classroom approach. T test. PowerPoint presentation

\section{Introduction}

Today, because of the great economic and technological changes and an ever-changing learning environment where everything becomes easily accessible, the education requires a new approach better suited to the fourth industrial revolution or Industry 4.0 which is enhanced with smart and autonomous systems and relied on networks enabling industry to adapt quickly to the speed with which things change (Benomar 2017). In fact, this industrial revolution requires new skills named the soft skills which are becoming more and more mentioned at the head of job offers' requirements (Gael 2017; 
Cursusproentreprise 2018). Therefore, the challenge for educators is to prepare students in order to develop a fuller array of competencies skills and knowledge in an ever-changing world.

Of course the technology have entered the field of education, however, it didn't seem to influence the pedagogies set up by teachers (Bernard and Veran 2014). Because it is not about employing the technology at all costs, but ensuring a quality education which means to meet conformity with the customer requirements or more specifically the real job requirements. That is to say, a quality education must promote socio-professional integration, ensure a better balance between the training and employment and so learning students to learn with technology and use information to get the skills which enable them to implement the new knowledge constantly appearing (Bernard and Veran 2014).

This is why actually, there is a rise to the emergence of a number of pedagogical methods such as flipped classroom or inverted classroom which is first popularized in secondary education in the United States and after it is being implemented in a growing number of higher education institutions. The flipped classroom method is described as an environment in which events that have traditionally taken place inside the classroom now take place outside the classroom and vice versa ( Papadopoulos and Aidsa 2010; Lape et al. 2014). This means that students have to prepare course content before coming to class for doing homework like solving exercises and problems. The main aim of this method is to free-up class time in order to promote active learning which has proven to improve understanding and retention and help students learn to take more responsibility for their own learning (Laman et al. 2012; Sara 2014; Thomas 2017). The most important benefit of the flipped classroom seen by various studies was developing learners' autonomy (Zamzami 2018). It was evident that the more students took responsibility for their own studies, the more they perceived themselves, and the more intrinsically motivated they were (Zamzami 2018; Zainuddin and Halili 2016).

Although the most of its proponents suggest recorded multimedia lectures to be viewed by students outside of the classroom, the founders and pioneers of flipped learning, Bergman and Sams have never required video using in flipped learning. Also the video hosting services apparition at the beginning of the 2000's like Youtube, Vimeo and Khan Academy postdates the initial uses of flipped classroom which go back to the mid 90's and early 00's (Robert 2017).

In fact, the Internet evolution to a collaborative web and the ability to host video, have led to the coupling of video and flipped learning. But this coupling mustn't drive people away from trying flipped learning if there is no requirement for the use of videos.

But, when flipping classroom, the challenge is always developing activities in order to gather effectiveness. Activities frequently used in class are based on exercises or problems solving usually by groups (Lape and Levy 2014; Stanley and Lynch 2014). In papers (Stanley and Lynch 2014; Thomas 2017), class time was reserved also for mini lecture besides problem solving. Shrestha 2016 proposes a team project workshop with the guidance and assistance of the instructor. Cabi 2018 utilizes group presentation and assessments in form of multiple choice questions about the course content done outside the classroom. In paper See and Conry 2014, In-class activities covered a quiz on the homework, evaluation and feedback of the cranes prepared by faculty instructors and reflections on individual, small and large groups.

Because there no description of what exactly must be done in and out of class, it is presented here, in this paper, an exemplary structure for a flipped classroom best suited to the Industry 4.0 and to the very changing environment in which it is imperative to train students in order to thrive in new and changing work situations where the knowledge have an extremely expiry date (Serap et al. 2006). That is to say, when the students apply what they know, it is already outdated. So, the structure aims at preparing students to have the soft skills needed in the Industry 4.0 especially, the self-learning, the lifelong learning, the critical thinking and the communication and presentation skills (Gael 2017; Gaetan et al. 2018). This structure was implemented in engineering school maintenance and operating reliability' course in the 2018-2019 academic year.

\section{Motivations and objectives}

During mentoring students in their end of study projects for the past two years, it was found that most of them suffered from a lack of soft skills. Generally, in higher education and due to the great number of students in the classroom, most of them have a little 
experience with oral presentation, while actually and especially with the fourth industrial revolution, the technical skills or hard skills of engineers alone is no longer sufficient to meet the demands of the market place (Tharwat 2013). In fact, the industry 4.0 requires engineers to have soft skills and several researches point out the need for engineers to be able to integrate technical skills with soft skills (Tharwat 2013; Cochrane 2009).

Therefore, the engineering students must have these skills in order to get success at the future working life where everything changes rapidly. These skills can best be improved through practice, improving the self-efficacy and engaging students in learning. This is why the flipped classroom with a new structure based on PowerPoint presentations was implemented.

\section{Structures and Methods}

\subsection{Methods}

During this study, a flipped classroom based on PowerPoint Presentations (FCPPP) was implemented in engineering school maintenance and operating reliability' course in the first semester of the 2018-2019 academic year. The school was the national school of applied sciences NSAS placed in Fez Morocco and the course was delivered for the industrial engineering class (IE). In the IE class, there were 34 students that met weekly for 4 hours during 13 weeks. The course is taught during the first semester of the fourth year of engineering studies.

In order to analyze the effectiveness of the FCPPP method, implementing the flipped method started in the third week. In the first two weeks, the course was delivered by adopting the traditional method which enabled me firstly to give a general ideas about the course contents before adopting the flipped method and secondly to compare the two methods. After the two first weeks, a pre-test was given to the two classes.

\subsection{Structure}

In the flipped classroom based on PowerPoint Presentations, for out of class activities, the students were assigned to prepare a PowerPoint presentation about certain part of the course. The students were divided into groups, with each group comprising a minimum of three and a maximum of four students. The groups had different subjects in order to cover the course's content. In total, each group has made two presentations.

During preparation, the students could refer to teacher's course text book and PowerPoint presentation. Also, it was recommended to search related ideas, further explanations and videos in the internet. They were obliged to follow the teacher's instructions related to the division of tasks, the time allocated for the presentation and the indication of bibliographic sources in order to ensure the information's reliability. They are told that their presentation should not exceed a maximum of 30 minutes. In each session, two groups presented their works.

The instructions related to the techniques of presentation were given by teacher after each presentation using thus the principle of the productive failure learning method. In this method, students explored, discussed and solved problems related to the new concepts first even though they might come across failures, followed by consolidating the concepts and associated procedures (Song and Kapur 2017).

Critical feedback was given to each student. They are told that they must take into account these critics and improve in the second presentation because the improvement mark was included in the final mark.

In order to ensure the students' engagement and the collaboration from all group members, the students were informed that the presentation mark count for 50 per cent of a student's final course mark and that the assessment is individual.

In each session, the group presents its work and after each presentation, we start discussions about the presentation contents; the students pose their questions to maximize learning and also the teacher pose his questions to the group firstly and secondly to the all students in order to evaluate the effort each group member is making, to better clarify the presentation contents and therefore to stimulate critical thinking. The advantages of discussion which is a cooperative learning form are:

- Promoting individual responsibility.

- Building students' sense of belonging within the classroom which enhances students' self-esteem. 
- Enhancing the ability to work in groups.

- Enhancing critical thinking.

Also, the teacher gives critical feedback to each group member about the presentations techniques and communication and about the effort of prepared work. Finally, during about an hour and half, the teacher explains and re-explains the contents covered in the session.

The second presentation deals with the examples of some end of study projects in maintenance and operating reliability. Each group must search in the NSAS's library, an example of end of study projects reports related to the maintenance and operating reliability. They must also understand this project especially the problematic, the methods used and the results and then present it with a critical eye in about 30 minutes. The objectives of this part are:

- Learning how to put into practice the knowledge acquired in the course related to maintenance and operating reliability.

- Acquiring the skills needed to respond technical problems.

- Deepening technical and scientific knowledge.

- Ma s tering new to o ls a ndexploring methodologies which are potentially applicable in industries.

- Having the opportunity to learn how to write a scientific report and to prepare a clear presentation about the project.

- Learning how to analyze the results obtained and drawing relevant conclusions.

The students' presentation assessment was based on the list of criteria stated bellow:

- Consistency and clarity in content.

- Details and organization of the work.

- Visual display (use of color, front choice, labels clarity and quality of print and figures, use of section headings and sub-headings, use of visual aids (photos and videos).
- Method of presentation which includes verbal communication (fluency in language, quality of voice and accuracy in language) and non verbal communication (body language and gestures and eye contact).

- Explanation and response to the questions of students and teacher.

- Improvement in the second presentation compared to the first presentation.

- Ability to criticize the resolution of the problem in the end of study part and to propose a more consistent and justified solutions if needed.

The following are some strengths of this method:

- Improving the soft skills especially working in group, PowerPoint presentation, discussions and communication.

- Managing discussions by the student, engaging the student and learning the other students by the group members. This increases retention of information. In fact, the learning pyramid illustrates that discussions enables retention of information with a percentage $50 \%$ and that learning others is more efficient in terms of retention of information with a percentage 90\% (Brooks 1993) (See Fig. 1).

- Engaging student by encouraging him to search improves his autonomy, his self-efficacy and the information literacy. The self-efficacy which refers to an individual's assessment of abilities to accomplish a task (Cassidy and Eachus 1998; Bandura 1997), can be enhanced by getting himself into difficulty and situations of effort (Gaetan et al. 2018) whilst being obliged to prepare a course part from $\mathrm{A}$ to $\mathrm{Z}$ and to learn this to others. The information literacy means the ability to search, manage and evaluate the information in the web (Serap et al. 2006).

- Promoting a lifelong learning by improving the autonomy, the self-efficacy, the retention of information, the critical thinking and the information literacy.

- Improving communication and presentation techniques. 


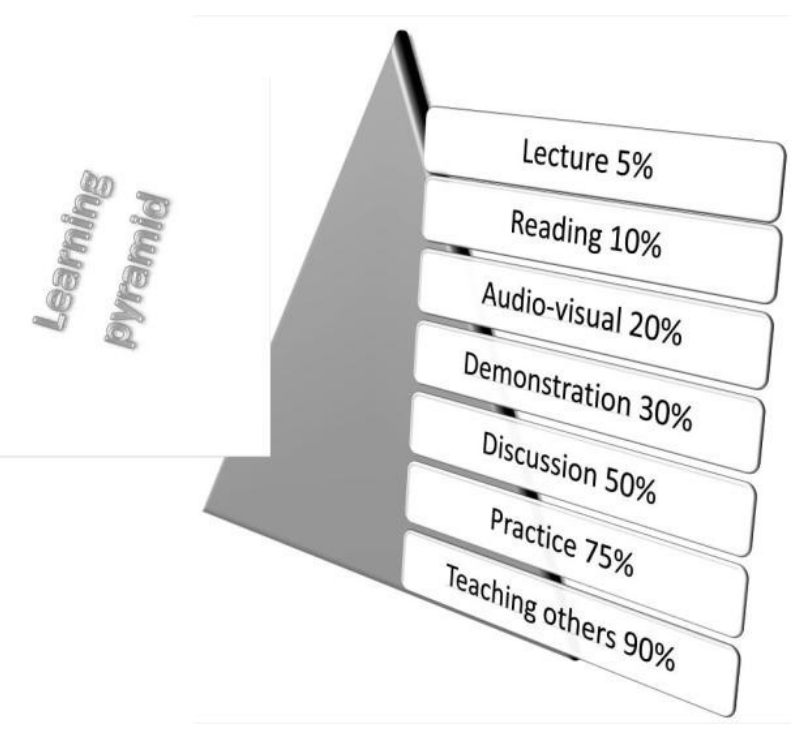

Fig. 1 : Learning pyramid

\section{Qualitative results}

An anonym survey was administered to the students at the end of the last session in order to evaluate the flipped classroom method. The survey includes closed questions and open questions.

It is noted that all students have submitted their survey responses.

As a result, $88 \%$ of students have preferred the flipped method based on PowerPoint presentation. 62 $\%$ of students have found this method very good and effective and $26 \%$ have found it good. In the other hand, $9 \%$ of students liked this method but preferred

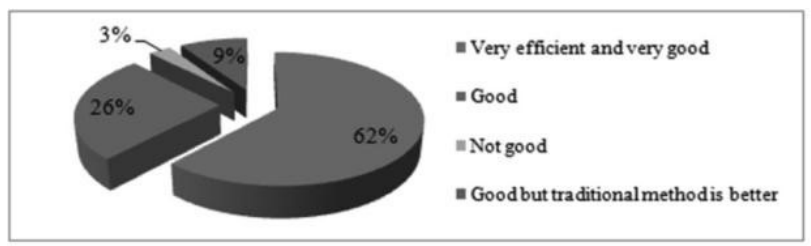

Fig. 2 : Students' feedback on the method

the traditional method while $3 \%$ of students didn't like this method (Fig. 2).

The students, who have disliked this method or preferred the traditional method, have justified this by the fact that the teacher has the ability to ensure a better understanding and that this method requires a great effort and time from the student to prepare the presentations. Then we can conclude that there was a very positive feedback from students for the inverted classroom based on PowerPoint presentations.

The students were also asked to report the benefits of the flipped classroom method in an open question. The frequencies associated to each benefit declared by students are presented in the Fig. 3 below. As seen, the best benefit which is perceived by $100 \%$ of students was public speaking skills and self-confidence improvement and also the benefit of the presentation techniques improvement with the same frequency. This was followed by knowledge enhancement by searching and discussions as mentioned by $67 \%$ and discussion techniques improvement as declared by 50 $\%$ of students. Also, $47 \%$ declared that this method enables good understanding and memorization of course content. This is justified by the fact that the discussions and teaching others used in this method improves the information retention. $30 \%$ of students see that this method improves self study and autonomy of student and that this method is a participatory approach and encourages searching. Besides, $26 \%$ of students declared that this method improves team spirit. $20 \%$ of students said this method enabled them to manage stress and to get used with presentations. Furthermore, this method improves the research techniques and information

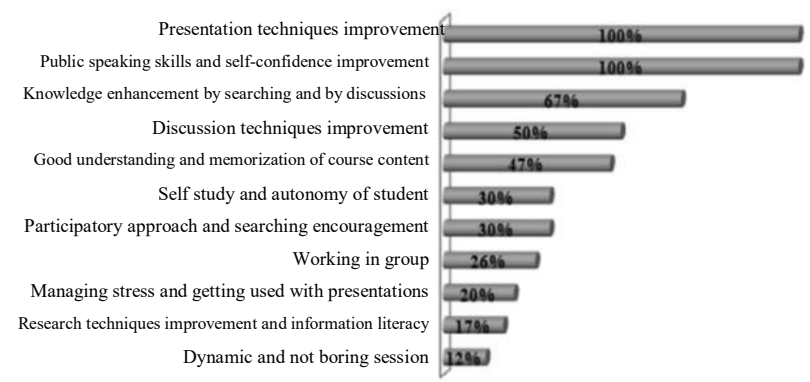

Fig. 3 : Benefits of the FCPPP method reported by the students

literacy as perceived by $17 \%$ of students. Also, dynamic, interactive and not boring sessions are the method's benefit see by $12 \%$ of students.

A closed question was addressed to the students about if this method enabled to be more motivated and encouraged to ask questions in the class. As a result, $88 \%$ of students approve that this method increased significantly their motivation and that they becoming more encouraged to ask questions, while $12 \%$ of students saw a little improvement in this sense (See Fig. 4 below) 
It is noted that there is a relation between the students who have disliked this method or preferred

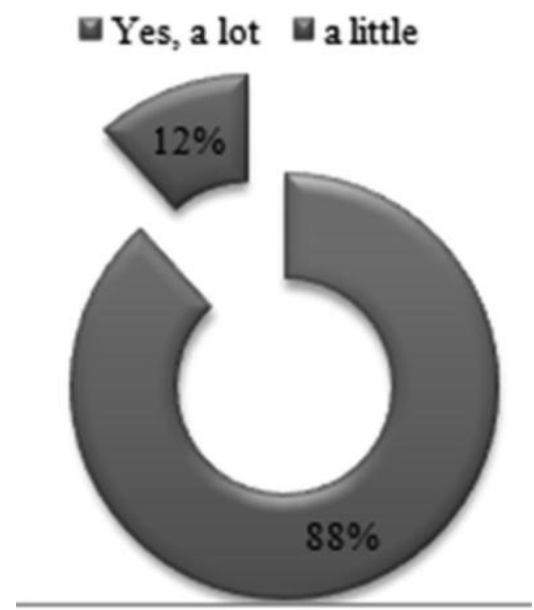

Fig. 4 : Students' feedback on the FCPPP method's benefit of improving the motivation and encouraging asking questions

the traditional method and the students who reported that there was a little improvement in their motivation and ability to ask questions. In fact, it is the same frequency.

Also, the students were asked to report the benefits of the second presentation about the end of study projects examples. $91 \%$ of students said that this method enables to learn how to deal with an end of study projects. The second benefit of this part reported

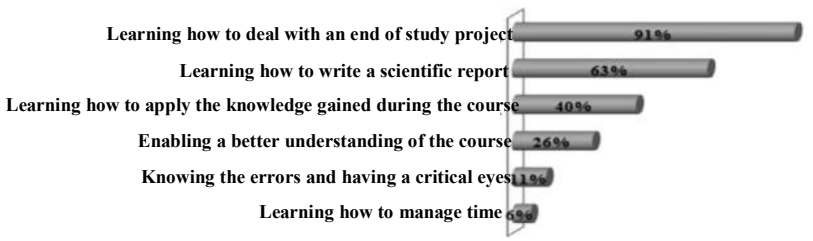

Fig. 5 : Benefits of the part of end of study project reported by the students

by $63 \%$ of students was learning how to write a technical report, followed by the benefit of learning how to apply the knowledge gained during the course with a frequency of $40 \%$. $26 \%$ of students confirmed that this part enabled them to better understand the course (Fig. 5 below).

Moreover, the most difficulties and their frequencies reported by students in an open question are shown in the Fig. 6 below. As it can be seen, the

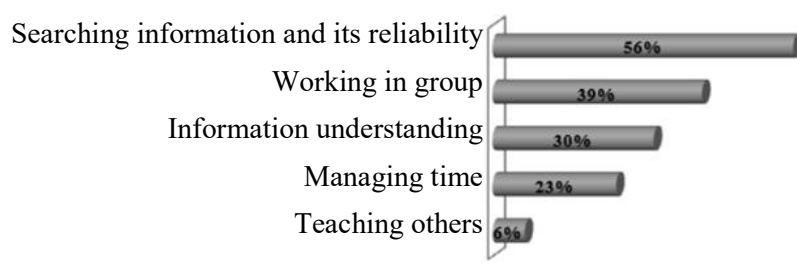

Fig. 6 : Difficulties in implementing the FCPPP method reported by the students

main difficulties were searching information and its reliability and working in group with the frequencies $56 \%$ and $39 \%$ respectively (See Fig. 6). This is followed by information understanding and managing time as perceived by $30 \%$ and $23 \%$ respectively.

As a conclusion, we have achieved the supposed objective that the flipped classroom based on PowerPoint presentation improves the student's soft skills especially the public speaking skills, the selfconfidence, the presentation techniques, working in group and the self learning and knowledge enhancing. Furthermore, the best difficulty encountered by more than half of the students in the class was how to search information and verify its reliability which was advantageous for them to improve searching techniques and so to improve the information literacy as declared by these students. Also, this method enables students to learn how to manage time which is essential for a lifelong learning. So, we can deduce that this method promotes a lifelong learning because it improves the information literacy, the self confidence, the self learning, the management of time and enhances knowledge.

Also, the method creates a dynamic and interactive climate as declared by an important number of students. We can also say that this method permit to a shy student to overcome her timidity in asking question because he asked a group of students like him as declared by a significant percentage of student.

From the great percentage of students who liked and preferred this method, we can deduce that there was a very positive feedback from students and below are some selected comments of students regarding the FCPPP approach:

- "This method is innovative and enriching. It has enabled us to get used to speak in public, to search information, to answer easily the questions asked and to deepen our knowledge because searching the information is not like finding it easily". 
- "This method is very enriching and is based on student centered approach. It involves students and facilitates understanding because it is based on PowerPoint presentations which are livelier than traditional lecturing".

- "Thanks to you teacher and to this method, I become more motivated and I am not afraid to face problem, to search any information in the internet and to ask questions".

- "We search the information ourselves, so we understand better and this leads to better retention of information".

- "I become more motivated to learn new things".

- "This method was an ideal opportunity for me to learn how manage time efficiently, to work in group, to criticize and to learn from the mistakes of others and to accept the remarks of my classmates".

- "It was difficult for us to find reliable sources of information but this has enabled us to learn information literacy".

- The end of study project part was an excellent initiative which enabled us to discover how to deal with a technical problem, the methods to solve it, how to present it and to write a report".

- "Thanks to this method, I become a self learner and I discovered a lot of information and techniques which are not present in the course content".

- "I am a shy person and rarely when I speak in the class even if I know the answers. But with this method, I become able to speak in public and I discovered that asking or being asked by someone is not the end of the world".

\section{Quantitative results}

In order to investigate differences between the

Table 1: T-test results applied for the IE class

\begin{tabular}{|l|c|r|r|r|r|}
\hline & Mean & \multicolumn{1}{|c|}{ N } & $\begin{array}{c}\text { Std. } \\
\text { deviation }\end{array}$ & $\begin{array}{c}\text { Mean } \\
\text { standard error }\end{array}$ & Sig \\
\hline Exam_score before FC & 12,8589 & 34 & 2,98003 &, 39345 & 0.032 \\
Exam_score after FC & 13,7671 & 34 & 2,03313 &, 34476 & \\
\hline
\end{tabular}

scores of exams before and after implementing the flipped method, t-test (the participants were the same in each condition) was used. The results of the t-test applied for the IE class are shown in the Table 1 using the IBM SPSS analytics tools.

From the results of the means value (M) and the standard deviations (SD), it can be seen that there was a significant difference in scores before and after implementing flipped learning, $\mathrm{M}=12.85$ and $\mathrm{SD}$ $=2.98$ without $\mathrm{FL}$ and $\mathrm{M}=13.76$ and 2.03 with FL (See Table 1). We can conclude that there is a significant difference in average exam scores because the significance (sig) value or the p-value is less than 0.05 , ensuring more than $95 \%$ confidence in the results.

\section{Conclusion}

The flipped classroom based on PowerPoint presentation is a very efficient method which promotes a lifelong learning and improves the soft skills which are becoming very important and very required in the digital age and for the industry 4.0. In fact, it improves the public speaking skills, the self-confidence, the presentation techniques, the information literacy, the self learning and knowledge enhancing and so promotes the lifelong learning.

Also, from the survey results, we can say that there was a very positive feedback from the students. For the teacher, she can say that there was a great change in each session compared to the sessions of the last two years where the course was delivered with the traditional method. The sessions were very dynamic especially the discussion part where everyone was engaged and which involves a critical thinking and a lot of ideas.

Furthermore, with using a t test, we can deduce that the method of FCPPP improves the academic achievement of students. Further researches are needed in order to study the effectiveness of this method in improving academic achievement.

We can conclude that this method enables a quality education with minimum technical, technological and logistical resources. It is a rewarding teaching experience but it requires more effort from the teacher who becomes rather a coach and a facilitator and also from the students who become a self-learners but 
which helps them to thrive in life.

\section{References}

[1] Bandura, A. (1997). Self-efficacy: The Exercise of Control, W.H. Freeman and Company, New York, NY.

[2] Basal, A. (2015).The implementation of a flipped classroom in foreign language teaching. Turkish Online Journal of Distance EducationTOJDE ISSN 1302-6488. 16, 4 (Oct. 2015).

[3] Benomar, R. (07 Dec 2017). L'industrie 4.0 aux portes du Maroc. Avai 1 able a t: https://www.leconomiste.com/article/10211121-industrie-4-0-aux-portes-du-maroc

[4] Bernard, C., Veran, J.P. (Dec 2014). Pédagogie et révolution numérique. Revue international d'education, sevres, $\mathrm{N}^{\circ} 67$.

[5] Brooks, J. and Brooks, M. (1993). In Search of Understanding: The Case for Constructivist Classrooms, ASCD, ISBN-10: 0-87120-358-8

[6] Cabi, E. (2018). The impact of the flipped classroom model on students' academin achivement. The International review of redearch in open and distributed learning, 19, 3 (Jul 2018).

[7] Cassidy, S., \& Eachus, P. (1998), "Developing the computer self-efficacy (CSE) scale: investigating the relationship between CSE, gender and experience with computers", Computer Self-Efficacy Web Site, available at:www.chssc. salford.ac. uk/healthSci/ selfeff/selfeff.htm

[8] Cochrane, T. (2009). Enhancing the oral presentation skills of engineering students: technology to the rescue with the virtual-I presenter (VIP). American society for engineering education

[9] Cursusproentreprise. (24 Jul 2018). Pouquoi la montée des formations en soft skills va $\mathrm{s}$ ' a c c e n t u e r, a v a i 1 a b 1 e a t : https://blog.cursuspro.com/pourquoi-monteeformations-soft-skills-va-saccentuer/

[10] Gael, B. (19 Sep 2017). Les soft skills au service de l'usinedufutur, available at: www.linkedin.com/pulse/les-soft-skills-auservice-de-lusine-du-futur-gael-bouron

[11] Gaetan, L., Marie, L., \& Emma, V. (21 Oct 2018). Soft skills: à quelles competences-clés peut-on vr a im e nt se for me $r$ ?, a $v$ a ila $b$ le a t : www.usinenouvelle.com/blogs/le-blog-desexperts-des-neurosciences/soft-skills-a-quellescompetences-cles-peut-on-vraiment-seformer.N772384

[12] Jungić, V., Kaur, H., Mulholland, J., \& Xin, C. (2015). On Flipping the classroom in large first year calculus courses. International Journal of Mathematical Education in Science and Technology, 46(4), 508-520.

[13] Laman, J. A., Brannon, M. L., \& Mena, I. B. (2012). Classroom flip in a senior-level engineering course and comparison to previous version. Paper presented at the American Society for Engineering Education Annual Conference, San Antonio, TX.Retrievedfrom h t t p : / / w w w a s e e.org/public/ conferences/8/papers/4028/view

[14] Lape, N. K., Levy, R., Yong, D. H. \& Hankel, N. (2014). Probing the inverted classroom; a controlled study of teaching and learning outcomes in undergraduate engineering and mathematics. 121st ASEE Annual Conference \& Exposition, Indianapolis, IN, June 15-18.

[15] Muir, T. (2017). Flipping the Mathematics Classroom: Affordances and Motivating Factors. The Mathematics Educator, 17, 1\&2, 105 - 130

[16]Papadopoulos, C . , Aidsa, S . (2010) . Implementing an Inverted Classroom Model in Engineering Statics: Initial Results. Paper presented at 2010 Annual Conference \& E x p o s i t i o n, L o u i s vi 11 e, K e n t u c k y. https://peer.asee.org/16768

[17] Robert, T. (2017). Flipped learning, a guide for higher education faculty. Published by stylus publications in May 2017.

[18] Sara, A. (2014). The flipped classroom teaching model and its use for information literacy instruction. Communications in Information Literacy . 8(1). 
[19] See, S., \& Conry, J. (2014). Flip My Class! A faculty development demonstration of a flipped-classroom. Currents In Pharmacy Teaching And Learning, 6(4), 585-588.

[21] Serap, S., Buket, A., \& Aysun, U. (2006). Developing the information literacy self-efficacy scale, Journal of documentation, 62 (6),

[22] Shrestha, S. (2016). Flipped classroom and project based learning. AAEE conference ( Coffs harbou, Australia)

[23] Stanley, R., Lynch, T. (2014). An innovative method to apply the flipped learning approach in engineering courses via web based tools. Proceedings of the 2014 ASEE Gulf-southwest conference organised by tulane university (new orleans, Louisiana).

[24] Song, Y., \& Kapur, M. (2017). How to Flip the Classroom - "Productive Failure or Traditional
Flipped Classroom" Pedagogical Design?. Educational Technology \& Society, 20 (1), 292-305.

[25] Tharwat, M. E (2013). Poster presentations improve engineering students' communication skills. International journal of education and practice, 1(7), 75-86

[26] Thomas, M. (2017). Flipping the chemical engineering process control class with elessons. ASEE Annual Conference \& Exposition (June 2017).

[27] Zainuddin, Z., \& Halili, S.H (2016). Flipped classroom research and trends from different fields of study. The international review of research in open and distributed learning, 17(3).

[28] Zamzami, Z. (2018). Students' learning performance and perceived motivation in gamified flipped class instruction. Computers\& education $126,75-88$ 